\title{
1 Fruit performance of kiwifruit in the loess area of 2 Northwest China
}

3 Kaibin Guo $^{1}$, Zhen Guo $^{2}$, Yun Guo ${ }^{3}$, Guang Qiao ${ }^{*}$

$4 \quad{ }^{1}$ Key Laboratory of Plant Resources Conservation and Germplasm Innovation in

5 Mountainous Region (Ministry of Education), Institute of Agro-Bioengineering/College

6 of Life Science, Guizhou University, Guiyang 520025, Guizhou Province, P. R. China;

$7 \quad{ }^{2}$ Shanxi Provincial Land Engineering Construction Group Co., Ltd., Xian 710075,

8 Shanxi, Province, P. R. China;

$9 \quad{ }^{3}$ Key Laboratory of Plant Nutrition and the Agri-Environment in Northwest China

10 (Ministry of Agriculture)/College of Natural Resources and Environment, Northwest A

11 \& F University, Yangling 712100, Shanxi Province, P. R. China; 


\section{Abstract}

Attempts had been made to provide evident insight into the performance of fruit quality and the status of soil property, and explicate the soil property factors that dominantly affect the fruit quality of kiwifruit. Currently, 8-year-old kiwifruit cultivar 'Hayward', which was grown in Zhouzhi County $\left(108^{\circ} 37^{\prime} \mathrm{E}, 33^{\circ} 42^{\prime} \mathrm{N}\right)$, Shanxi

Province of China, was used as materials. The results of Pearson correlation coefficient illustrated that the soil organic matter (SOM) content was positively related to soil properties except the soil $\mathrm{PH}$. Moreover, based on the canonical correlation analysis (CCA), canonical variables alkaline hydrolyzable-N (AN), available ferrum (AFe), available boron $(\mathrm{AB}), \mathrm{PH}$ in soil property index and the fresh weight of single fruit (FW), fruit shape index (FI), total soluble solids (TSS), titratable acidity (TA), total soluble sugar (SS) in fruit quality parameter were selected. And the 'best' regression equation (model) indicated that the effects of soil property somewhat varied among 'Hayward' fruit qualities in the loess area of Northwest China. Specifically, FW and SS could be mainly affected by soil AN, and 
FI affected by soil AB and PH. Fruit SS mostly depended upon soil AFe, whereas TSS was affected by soil AN, AFe and PH. The effect of soil PH on fruit quality is probably achieved, however, affecting the absorption of soil nutrients.

Keywords: Actinidia Chinensis; Fruit quality; Soil property; Northwest China

\section{Introduction}

As an edible berry of several Actinidia species, kiwifruit is unequalled, compared

with other commonly consumed fruit, for their rich antioxidant, health benefits, and consumer appeal [1]. The successful development of kiwifruit industry was first

appeared in New Zealand, and then expanded rapidly in other countries. Over the past decade, large amount of kiwifruit had been planted in China due to the strongly economic incentive caused by the international kiwifruit trade [2]. Among many factors that affect economic benefit of fruit, fruit quality plays a pivotal role in consumption choice, agro-industrial processing, food technology, and production data.

Normally, the fruit quality was determined by both cultivar and growing environment, which was confirmed on many tree species, e.g. blueberry [3], citrus [4], apple [5]. Likewise, the difference on fruit quality of kiwifruit in terms of sensory 
acceptance, sugar and nutritive factors as well as polyphenols among cultivars were reported by previous studies [6,7], which was affected by tree canopy density [8], ambient temperature [9], soil water potential as well [10]. Particularly, previous surveys illustrated that soil nutrient is of utmost importance for fruit quality of kiwifruit. For instance, Hasinurrahman et al. [11] provided a indirect evidence that kiwifruit quality mostly depended upon the use of a biological farming system, which linked with the soil properties. Lago et al. [12] found that the $\mathrm{K}: \mathrm{Mg}$ ratio in soil was closely related to the absorption of $\mathrm{Ca}^{2+}$ and $\mathrm{Mg}^{2+}$ by kiwifruit. The level of soil nutrient, however, majorly depended on the environmental conditions, e.g.,topography, climate and man- induced factors, e.g., agricultural management [13,14]. For instance, Khan et al. [4] reported that the orchard location and soil nutrient status play a crucial role in fruit quality of citrus in Sargodha city of Pakistan. Zhouzhi, a county of Guanzhong plain, Shanxi Province of China, where the soil type are primarily composed of anthrosol, which is super common type in the loess area of Northwest China. Researchers had previously applied the Pearson correlation coefficient for predicting the relationship between fruit quality of kiwifruit and anthrosol type soil in Northwest China. But in the present work, the canonical correlation analysis (CCA) method was applied to select the main soil properties factors affecting fruit quality. And then the method of stepwise multiple regression was used for establishing the 'best' regression equation (model). Therefore, the objectives of the work are: (a) assessing of the performance of fruit quality and the status of soil nutrient, and exposing of the mutual relationship; (b) based on the 
method of multivariate analysis, illustrating the soil nutrient factors that dominantly affect the fruit quality of kiwifruit in Northwest China.

\section{Materials and methods}

\section{Plant material and soil sample}

Currently, a well-known kiwifruit cultivar 'Hayward', which was grown in Zhouzhi County $\left(108^{\circ} 37^{\prime} \mathrm{E}, 33^{\circ} 42^{\prime} \mathrm{N}\right)$, Shanxi Province of China (Fig 1), were sampled as materials in 2018. The climate of the orchard belongs to a warm temperate continental monsoon climate, characterized by the average total annual precipitation of 850.52 $\mathrm{mm}$ and the mean annual sunshine hours of $1,774.6 \mathrm{~h}$ as well as average annual temperatures of $14.3{ }^{\circ} \mathrm{C}$. The 8-year-old kiwifruit trees were planted in the row spacing of $4 \mathrm{~m} \times 5 \mathrm{~m}$ and grown to the height about $4.5 \mathrm{~m}$. At the stage of fruit mature (from early August to end September), a sample of randomly obtained 12 fruits were harvested from East, South, West and North of each tree (three trees per replication), and quickly frozen in ice box with under $-20{ }^{\circ} \mathrm{C}$. Soil in this area is mainly a type of earth-cumuli-orthic anthrosols. The average soil bulk density in soil layer depth $0-40$ $\mathrm{cm}$ is about $1.35-1.62 \mathrm{~g} \cdot \mathrm{cm}^{-3}$. To approach more representative data, soil was sampled randomly from three distantly separated plots, which was consisted of three replicates of nine trees, from June to August. Soil in $0-40 \mathrm{~cm}$ layer was collected with soil drilling method from East, South, West and North of each tree crown vertically inward $50 \mathrm{~cm}$, and were air-dried naturally at room temperature and crushed, before been sieving through a 2-mm mesh sieve. 


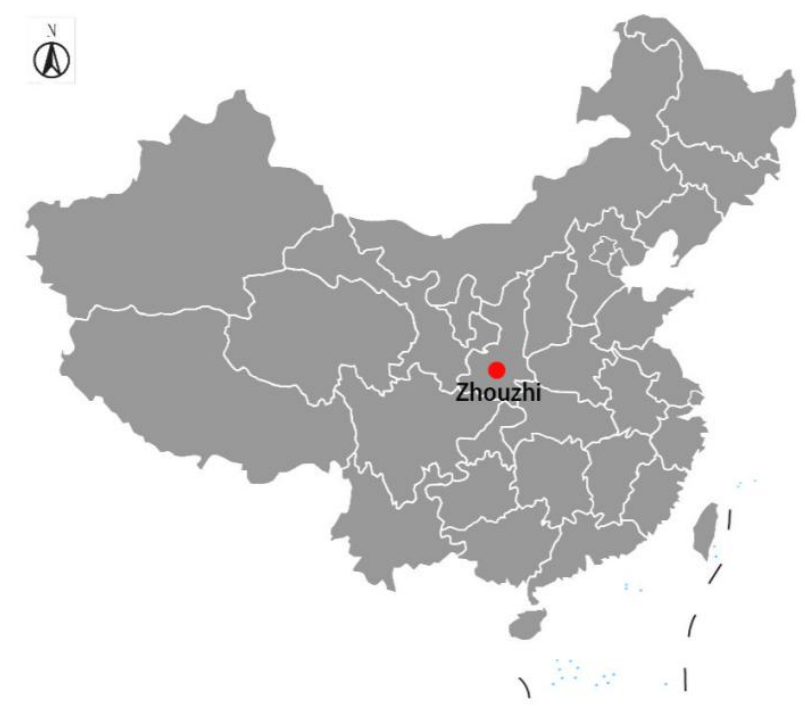

Fig 1. Geographical location of sampling sites in China

\section{Determination the performance of fruit quality}

\section{Weight and shape index}

The fresh weight of single fruit (FW, expressed in g) was determining on an analytical balance (Mettler-Toledo AL204). The fruit height and width (expressed in mm) were measuring by a Vernier caliper (Nscing Es, China) and calculating fruit shape index (FI) as height/width ratio. Three replications were conducted and averaged the value.

These levels were assessed with juice obtained randomly from three fruits per replication. Juice was obtained from fruit center using the indelicate super automatic extractor (SamTech, Mannersdorf, Austria). The concentration of total soluble solids (TSS) were determined at $20{ }^{\circ} \mathrm{C}$ using a refractometer (SHGWYT-2, 0-32\%, China) and reported as ${ }^{\circ}$ Brix. Titratable acidity (TA) was determined by titration with 0.05 
113

114

115

116

117

mol L $\mathrm{L}^{-1} \mathrm{NaOH}$ to $\mathrm{PH} 8.2$ and reported as g citric acid per $100 \mathrm{~g}$ fresh weight. Total soluble sugar (SS) was measured through anthrone- $\mathrm{H}_{2} \mathrm{SO} 4$ colorimetry and expressed in ${ }^{\circ}$ Brix.

\section{Detection the property of soil}

Total organic matter content was gravimetrically determined by loss on ignition $\left(\mathrm{OM}_{\mathrm{LOI}}\right)$. Briefly, $10 \mathrm{~g}$ samples were oven-dried at $105{ }^{\circ} \mathrm{C}$ overnight, weighed, ignited to equilibrium in a muffle furnace set at $350{ }^{\circ} \mathrm{C}$ for $18 \mathrm{~h}$ and reweighed. The lower ignition temperature was chosen to prevent errors from high loss of structural water from kaolinite clays which is generally greatest between 450 and $600{ }^{\circ} \mathrm{C}$ [15]. The total nitrogen $(\mathrm{TN})$ was measured by the Kjeldal method, while $\mathrm{PH}$ was determined using 1:2.5 $\mathrm{CaCl}_{2}$ dilution method [16]. Alkaline hydrolyzable-N (AN) in soil was assessed with a micro-diffusion technique after samples went through alkaline hydrolysis. Soil available phosphorus (AP) was determined by the Olsen method [17]. Soil available potassium (AK) was measured in $1 \mathrm{~mol} \mathrm{~L}^{-1} \mathrm{NH}_{4} \mathrm{OAc}$ extracts by flame photometry. DTPA-extractable micronutrients, i.e., available ferrum (AFe), available Zinc $(\mathrm{AZn})$, available boron $(\mathrm{AB})$ contents in soil were measured on atomic absorption spectrophotometer (4530F China) from 1:2 soil-extractant ratio using DTPA-TEA buffer $\left(0.005 M\right.$ DTPA $+0.001 M \mathrm{CaCl}_{2}+0.1 M$ TEA, pH 7.3) with method described by Lindsay \& Norvell (1978) [18].

\section{Statistical Analysis}

Pearson's correlation analysis (PCA) was used to evaluate the Pearson correlation 
coefficient between the fruit quality values and soil nutrient levels by SPSS 22.0 statistical software. And heatmap was drawn by $\mathrm{R}$ package function heatmap. 2 (http://cran.r-project.org/web/packages/gplots/index.tml).

According to the modern regression theory, soil nutrients and fruit qualities belong to two different normal distributions, and each variable set consisting of more than two variables. To model the response variable as a function of one or more predictor variables. CCA completing by 'Sytax' macro program of SPSS, was employed for assessing the relationship between the soil nutrients, i.e., $\mathrm{OM}\left(\mathrm{x}_{1}\right), \mathrm{TN}\left(\mathrm{x}_{2}\right), \operatorname{AN}\left(\mathrm{x}_{3}\right)$, $\mathrm{AP}\left(\mathrm{x}_{4}\right), \mathrm{AK}\left(\mathrm{x}_{5}\right), \operatorname{AFe}\left(\mathrm{x}_{6}\right), \mathrm{AZn}\left(\mathrm{x}_{7}\right), \mathrm{AB}\left(\mathrm{x}_{8}\right), \mathrm{PH}\left(\mathrm{x}_{9}\right)$ as independent set of variables and fruit qualities, i.e., $\mathrm{FW}\left(\mathrm{y}_{1}\right), \operatorname{FI}\left(\mathrm{y}_{2}\right), \operatorname{TSS}\left(\mathrm{y}_{3}\right), \operatorname{SS}\left(\mathrm{y}_{4}\right), \mathrm{TA}_{\left(\mathrm{y}_{5}\right)}$ as dependent set. Then, the method of stepwise multiple linear regression(SMLR) was used alternatively to build linear regression prediction equations (models) by SPSS 22.0 software.

\section{Results}

\section{Quality performance of fruit and property status of soil}

Performance of fruit quality were presented in Table 1. The FW values ranged from 77.63 to $91.12 \mathrm{~g}$ with a mean of $84.49 \mathrm{~g}(\mathrm{STD}=5.12, C . V .=6.00 \%)$, while FI levels varied from 1.09 to 1.30 with an average of $1.20(\mathrm{STD}=0.07, C . V .=6.00 \%)$. As for the internal qualities of kiwifruit fruit, i.e., TSS, SS, and TA, which were used to calculate values of the TSS/TA and SS/TA. Contents of TSS and SS ranged from 
155

156

157

158

159

160

161

162

163

164

165

166

167

to $10.00^{\circ}$ Brix with an average of $9.01^{\circ}$ Brix $(\mathrm{STD}=0.66, C . V .=7.00 \%)$, respectively.

Whereas TA concentration varied from 1.12 to $1.33 \%$ with a mean of $1.23 \%$ ( $\mathrm{STD}=0.08, C . V .=7.00 \%$ ). The $\mathrm{TSS} / \mathrm{TA}$ and $\mathrm{SS} / \mathrm{TA}$ estimates varied from 9.77 to 11.95 with a mean of $11.16(\mathrm{STD}=0.89, C . V .=8.00 \%)$ and 6.11 to $8.93(\mathrm{STD}=0.98$, C.V. $=13.00 \%)$.

Table 1. Fruit quality of 'Hayward' kiwifruit

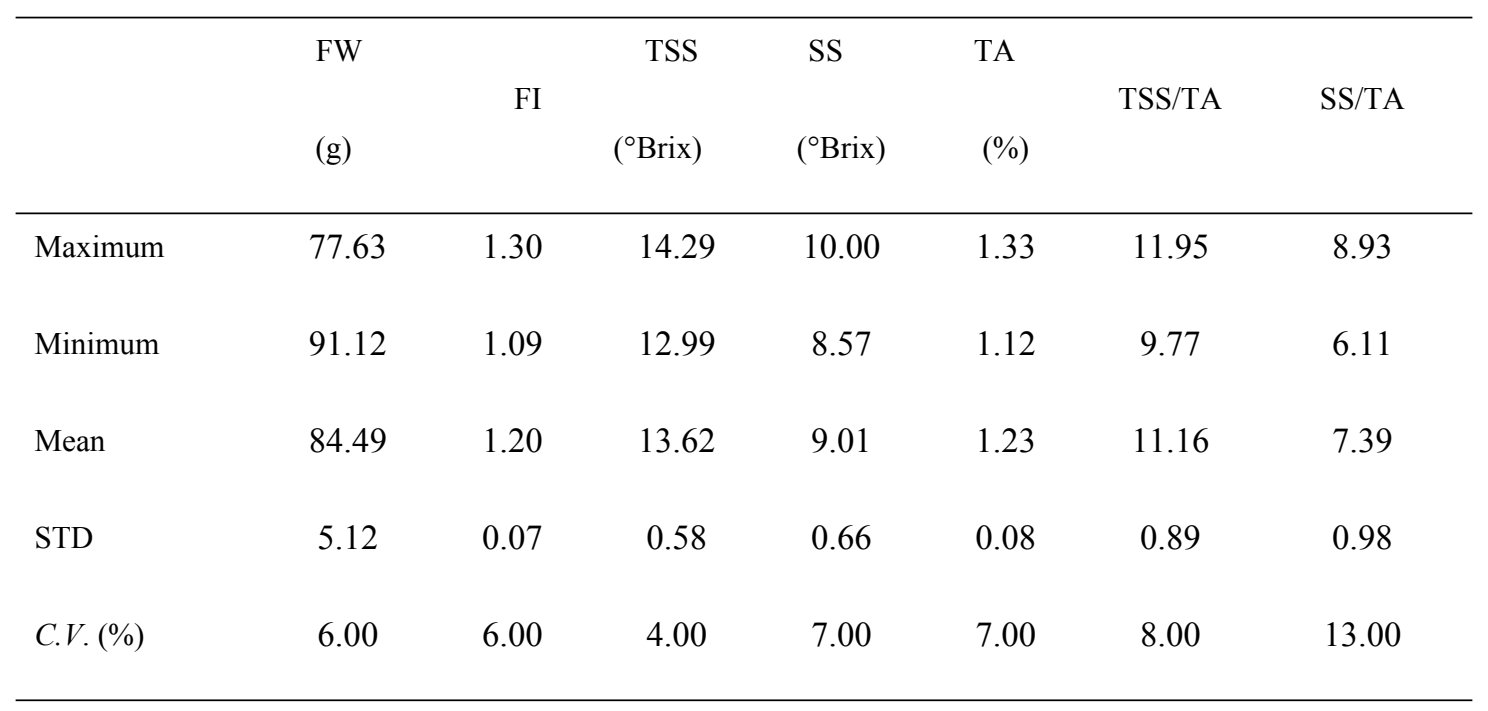

Note: 'STD' and 'C.V.' stand for standard deviation and coefficient of variation respectively.

Status of the studied soil properties were shown in Table 2. The OM contents of the samples varied from 22.75 to $24.10 \mathrm{~g} \cdot \mathrm{Kg}^{-1}$ with an average of $23.43 \mathrm{~g} \cdot \mathrm{Kg}^{-1}$ $(\mathrm{STD}=0.53, C . V .=2.27 \%) . \mathrm{TN}$ and $\mathrm{AN}$ statues with different order of magnitude, ranged from 1.46 to $1.61 \mathrm{~g} \cdot \mathrm{Kg}^{-1}$ with a mean of $1.55 \mathrm{~g} \cdot \mathrm{Kg}^{-1}(\mathrm{STD}=0.06, C . V .=3.81 \%)$ and 104.95 to $109.05 \mathrm{mg} \cdot \mathrm{Kg}^{-1}$ with an average of $107.17 \mathrm{mg} \cdot \mathrm{Kg}^{-1} \quad(\mathrm{STD}=1.76$, C.V. $=1.64 \%$ ) respectively. Moreover, the estimates of AP, AK, AFe with an average of $94.45 \mathrm{mg} \cdot \mathrm{Kg}^{-1}, \quad 110.95 \mathrm{mg} \cdot \mathrm{Kg}^{-1}, 9.11 \mathrm{mg} \cdot \mathrm{Kg}^{-1}$, varied from 89.86 to 106.73 $\mathrm{mg} \cdot \mathrm{Kg}^{-1}(\mathrm{STD}=6.37$, C.V. $=6.74 \%), 107.32$ to $114.01 \mathrm{mg} \cdot \mathrm{Kg}^{-1} \quad(\mathrm{STD}=2.83, C . V$. 
$170=2.55 \%)$ and 8.73 and $9.51 \mathrm{mg} \cdot \mathrm{Kg}^{-1}(\mathrm{STD}=0.27$, C.V. $=2.91 \%)$, respectively.

171 Furthermore, the $\mathrm{AZn}$ and $\mathrm{AB}$ values of sampled soils ranged from 0.92 to 1.08

$172 \mathrm{mg} \cdot \mathrm{Kg}^{-1}$ with a mean of $0.98 \mathrm{mg} \cdot \mathrm{Kg}^{-1}$ and 0.53 to $0.63 \mathrm{mg} \cdot \mathrm{Kg}^{-1}$ with an average of

$1730.57 \mathrm{mg} \cdot \mathrm{Kg}^{-1}$. Afterwards, the levels of soils $\mathrm{PH}$ varied from 6.15 to 7.39 with an

174 average of $6.95(\mathrm{STD}=0.42, C . V .=6.06 \%)$.

175 Table 2 Nutrient status of the studied soil

\begin{tabular}{lccccccccc}
\hline & OM & TN & AN & AP & AK & AFe & AZn & AB & \\
& $\mathrm{g} \cdot \mathrm{Kg}^{-1}$ & $\mathrm{~g} \cdot \mathrm{Kg}^{-1}$ & $\mathrm{mg} \cdot \mathrm{g}^{-1}$ & $\mathrm{mg} \cdot \mathrm{Kg}^{-1}$ & $\mathrm{mg} \cdot \mathrm{Kg}^{-1}$ & $\mathrm{mg} \cdot \mathrm{Kg}^{-1}$ & $\mathrm{mg} \cdot \mathrm{Kg}^{-1}$ & $\mathrm{mg} \cdot \mathrm{Kg}^{-1}$ & \\
\hline Maximum & 24.10 & 1.61 & 109.05 & 106.73 & 114.01 & 9.51 & 1.08 & 0.63 & 7.39 \\
Minimum & 22.75 & 1.46 & 104.95 & 89.86 & 107.32 & 8.73 & 0.92 & 0.53 & 6.15 \\
Mean & 23.43 & 1.55 & 107.17 & 94.45 & 110.95 & 9.11 & 0.98 & 0.57 & 6.95 \\
STD & 0.53 & 0.06 & 1.76 & 6.37 & 2.83 & 0.27 & 0.06 & 0.04 & 0.42 \\
C.V. (\%) & 2.27 & 3.81 & 1.64 & 6.74 & 2.55 & 2.91 & 6.19 & 7.61 & 6.06 \\
\hline
\end{tabular}

Results of correlation analyses of fruit qualities and soil properties were shown in

177 Fig 2. As for the soil properties, OM content showed a positive correlation with others

178 measured parameters except for the soil $\mathrm{PH}$, which showed significant negative

179 correlation with AP level $\left(R=-0.860^{*}\right)$. Moreover, obvious correlation among some

180 fruit traits were found as well, such as FW was positively and significantly correlated

181 with SS content $\left(R=0.813^{*}\right)$ and TSS/TA $\left(R=0.885^{*}\right)$; SS content was significantly

182 positive correlated with TSS/TA $\left(R=0.889^{*}\right)$ and SS/TA $\left(R=0.964^{* *}\right)$, whereas

183 remarkably negative correlation with TA concentration $(R=-0.821 *)$; TSS/TA showed

184 significantly positive correlation with SS/TA $\left(R=0.898^{*}\right)$ while obviously negative 
185

correlation TA $(R=-0.862 *)$, which showed significantly negative correlation with SS/TA $\left(R=-0.940^{* *}\right)$. Furthermore, statistically significant positive or negative correlation between fruit traits and soil properties were observed. Soil AN content was negatively and significantly correlated with fruit TA $\left(R=-.955^{* *}\right)$, however, positively and obviously correlated with TSS/TA $\left(R=0.863^{*}\right)$ and SS/TA $\left(R=0.902^{*}\right)$. Soil Fe content showed significantly positive correlation with fruit TSS concentration $\left(R=0.838^{*}\right)$.

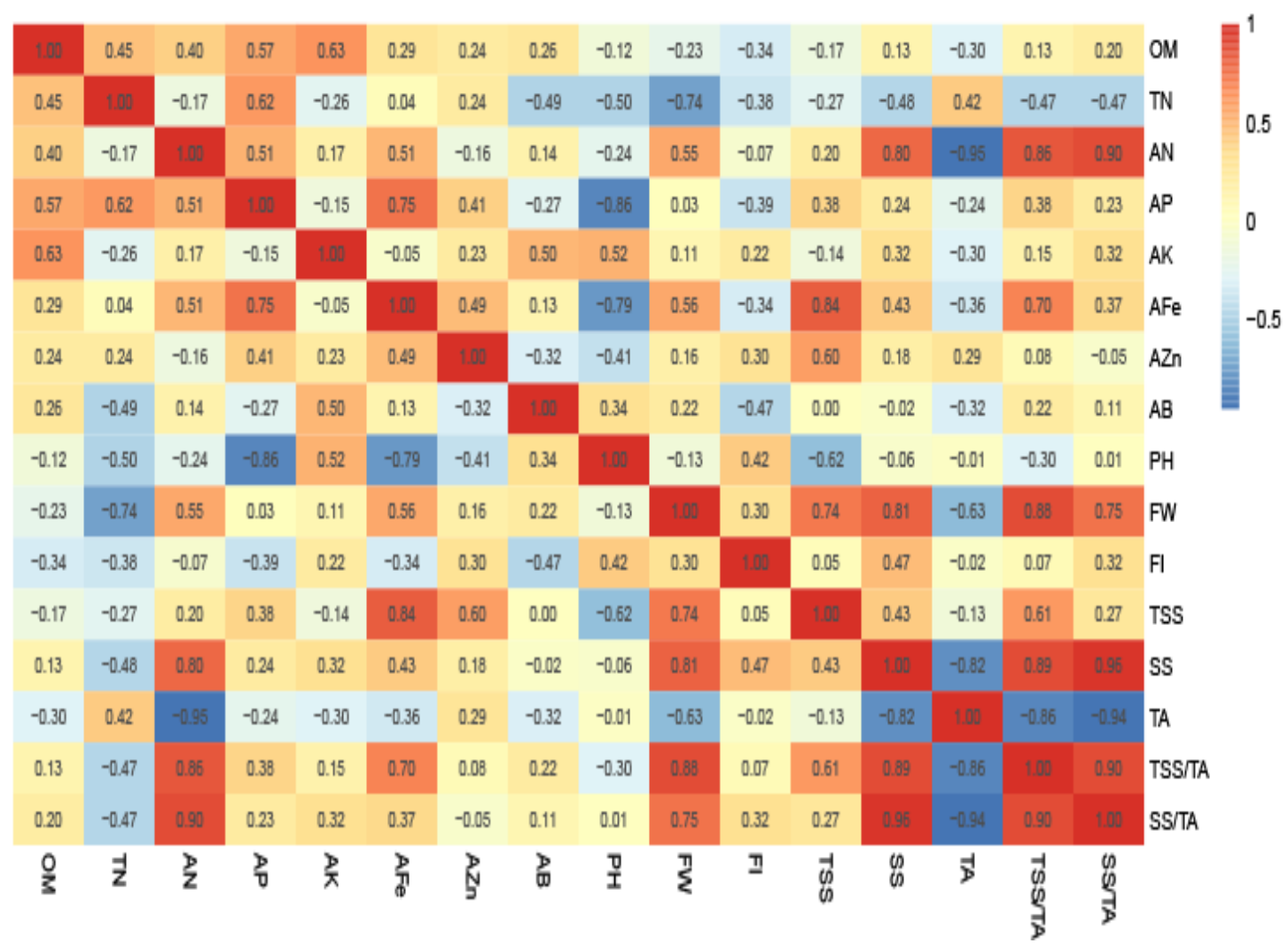

Fig 2. Pearson correlation heatmap of fruit qualities and soil nutrients.

Multivariate analysis of relationship between soil property and fruit 
197

\section{CCA of soil nutrient and fruit quality}

Results of CCA were revealed in Table 3. According to Wilk's $\lambda$ and Chi-square tests for canonical correlation coefficients, three pairs of canonical variables $\left(U_{l}, V_{1} ; U_{2}, V_{2}\right.$; $U_{3}, V_{3}$ ) of soil property and fruit quality, of which the canonical correlation coefficient and $p$-value for these canonical variables were 1.000 and $0.000,1.000$ and 0.000 , 0.987 and 0.001 respectively, all reached a significant level. The three pairs of canonical variables for soil property and quality could be described as follows:

$U_{l}=-0.201 \mathrm{x}_{1}+0.274 \mathrm{x}_{2}+0.564 \mathrm{x}_{3}+0.435 \mathrm{x}_{4}+0.137 \mathrm{x}_{5}-0.662 \mathrm{x}_{6}-0.128 \mathrm{x}_{7}-0.322 \mathrm{x}_{8}+1.07 \mathrm{x}_{9}$

$V_{l}=-0.199 \mathrm{y}_{1}+0.352 \mathrm{y}_{2}-0.807 \mathrm{y}_{3}+0.453 \mathrm{y}_{4}-0.187 \mathrm{y}_{5}$

$U_{2}=-0.147 \mathrm{x}_{1}+0.247 \mathrm{x}_{2}-1.015 \mathrm{x}_{3}+0.035 \mathrm{x}_{4}+0.168 \mathrm{x}_{5}-0.523 \mathrm{x}_{6}-0.067 \mathrm{x}_{7}-0.205 \mathrm{x}_{8}-0.02 \mathrm{x}_{9}$

$V_{2}=0.262 \mathrm{y}_{1}+0.189 \mathrm{y}_{2}-0.568 \mathrm{y}_{3}+0.034 \mathrm{y}_{4}+1.115 \mathrm{y}_{5}$

$U_{3}=-0.218 \mathrm{x}_{1}-0.283 \mathrm{x}_{2}-0.5 \mathrm{x}_{3}+0.295 \mathrm{x}_{4}-0.007 \mathrm{x}_{5}-0.666 \mathrm{x}_{6}-0.463 \mathrm{x}_{7}+0.8 \mathrm{x}_{8}-0.782 \mathrm{x}_{9}$

$V_{3}=1.394 \mathrm{y}_{1}-0.754 \mathrm{y}_{2}-0.705 \mathrm{y}_{3}-0.873 \mathrm{y}_{4}+0.169 \mathrm{y}_{5}$

For the first pair of canonical variables, $\mathrm{AN}\left(\mathrm{x}_{3}\right), \mathrm{AFe}\left(\mathrm{x}_{6}\right), \mathrm{PH}\left(\mathrm{x}_{9}\right)$ in soil nutrient index and $\operatorname{TSS}\left(\mathrm{y}_{3}\right)$ in fruit quality index presented greater weight coefficient. It illustrated that the contents of soil $\mathrm{AN}, \mathrm{AFe}$ and $\mathrm{PH}$ value played a crucial role in the levels of fruit TSS. The second pair of canonical variables $\left(U_{2}, V_{2}\right)$ where the dominant factors are $\operatorname{AN}\left(x_{3}\right), \operatorname{AFe}\left(x_{6}\right)$ in soil nutrient index, and $\operatorname{TSS}\left(y_{3}\right), \operatorname{TA}\left(y_{5}\right)$ in fruit quality index.

Similarly, the results indicated that the contents of AN, AF have dramatic impact not only on fruit TSS level, but also on TA concentration. Furthermore, $\operatorname{AFe}\left(\mathrm{x}_{6}\right), \operatorname{AB}\left(\mathrm{x}_{8}\right)$, $\operatorname{PH}\left(\mathrm{x}_{9}\right)$ in soil nutrient index and $\mathrm{FW}\left(\mathrm{y}_{1}\right), \mathrm{FI}\left(\mathrm{y}_{2}\right), \operatorname{TSS}\left(\mathrm{y}_{3}\right), \operatorname{SS}\left(\mathrm{y}_{4}\right)$ in fruit quality index 
218 of the third pair of canonical variables appeared a larger weight coefficient as well. It

219 also showed that FW, FI, TSS, SS were obviously affected by the contents of soil AFe,

$220 \mathrm{AB}$, and $\mathrm{PH}$ value. Additionally, with canonical redundancy analysis, $9.1 \%, 12.9 \%$,

221 and $11.3 \%$ of the variance of soil nutrient could be explained by the canonical

222 variables $V_{1}, V_{2}$, and $V_{3}$, respectively. And $21.9 \%, 27.6 \%$, and $14.8 \%$ of the variance

223 of fruit quality could be explained by the canonical variables $U_{1}, U_{2}$, and $U_{3}$.

Table 3. Wilk's $\lambda$ and Chi-square tests of canonical correlation coefficients

\begin{tabular}{lccccc}
\hline canonical & canonical correlation & Wilk's $\lambda$ & $\chi^{2}$ & df & $p$ \\
vector No. & coefficients & & & & \\
\hline 1 & 1.000 & 0.000 & 869.829 & 45 & $0.000^{* *}$ \\
2 & 1.000 & 0.000 & 463.298 & 32 & $0.000^{* *}$ \\
3 & 0.987 & 0.005 & 61.430 & 21 & $0.001^{* *}$ \\
4 & 0.894 & & & 12 & 0.083 \\
5 & 0.188 & 19.246 & 12 & 0.979 \\
\hline
\end{tabular}

Note: ' $* *$ ' indicated significance at $p<0.01$ level

By establishing SMLR equation between dependent and independent variable, and automatically eliminate from the selected equation the insignificant independent variables, and $F$-value were used to evaluate statisical significance of SMLR model. 
232 and $\mathrm{SS}\left(\mathrm{y}_{4}\right)$, whereas was negatively related to $\mathrm{TA}\left(\mathrm{y}_{5}\right)$. Moreover, $\mathrm{AFe}\left(\mathrm{x}_{6}\right)$ showed

233 positive correlation with $\operatorname{TSS}\left(\mathrm{y}_{3}\right)$ while negative correlation with $\mathrm{TA}\left(\mathrm{y}_{5}\right)$. Furthermore,

$234 \mathrm{AB}\left(\mathrm{x}_{8}\right)$ was negatively related to $\mathrm{FI}\left(\mathrm{y}_{2}\right)$. Additionally, $\mathrm{PH}\left(\mathrm{x}_{9}\right)$ was positively related to

$235 \mathrm{FI}\left(\mathrm{y}_{2}\right)$, but negatively related to $\mathrm{TA}\left(\mathrm{y}_{5}\right)$.

Table 4. The stepwise regression equations and $F$-value for soil nutrient to fruit quality

\begin{tabular}{lllll}
\hline Fruit qualities & Soil nutrients & Regression equations & $R^{2}$ & $F$-value \\
\hline $\mathrm{FW}\left(\mathrm{y}_{1}\right)$ & $\mathrm{OM}\left(\mathrm{x}_{1}\right), \mathrm{TN}\left(\mathrm{x}_{2}\right)$ & $\mathrm{y}_{1}=1.18 \mathrm{x}_{3}-41.878$ & 0.191 & $5.496^{*}$ \\
$\mathrm{FI}\left(\mathrm{y}_{2}\right)$ & $\mathrm{AN}\left(\mathrm{x}_{3}\right), \mathrm{AP}\left(\mathrm{x}_{4}\right)$, & $\mathrm{y}_{2}=-1.377 \mathrm{x}_{8}+0.09 \mathrm{x}_{9}+1.731$ & 0.366 & $6.475^{* *}$ \\
$\mathrm{TSS}\left(\mathrm{y}_{3}\right)$ & $\mathrm{AK}\left(\mathrm{x}_{5}\right), \mathrm{AFe}\left(\mathrm{x}_{6}\right)$ & $\mathrm{y}_{3}=0.884 \mathrm{x}_{6}+5.541$ & 0.525 & $21.999^{* * *}$ \\
$\mathrm{SS}\left(\mathrm{y}_{4}\right)$ & $\mathrm{AZn}\left(\mathrm{x}_{7}\right), \mathrm{AB}\left(\mathrm{x}_{8}\right)$ & $\mathrm{y}_{4}=0.188 \mathrm{x}_{3}-11.124$ & 0.258 & $7.610^{*}$ \\
$\mathrm{TA}\left(\mathrm{y}_{5}\right)$ & $\mathrm{PH}\left(\mathrm{x}_{9}\right)$ & $\mathrm{y}_{5}=-0.045 \mathrm{x}_{3}-0.028 \mathrm{x}_{6}-0.072 \mathrm{x}_{9}+6.771$ & 0.971 & $215.303^{* * *}$ \\
& & & & \\
\hline
\end{tabular}

Note: '*', '**' and '***' indicated significance at $\mathrm{p}<0.05,<0.01,<0.001$ level, respectively.

\section{Discussion}

240 Currently, difference in status of soil property was observed when comparing with the same soil type and land using same patial distribution, same climate condition in other

242 regions of China [19-21]. It was elucidated that the level of soil property was affected

243 by many interacting factors. Moreover, fruit quality of 'Hayward' cultivar in the 244 studied orchard also has discrepancy to other orchards [22,23]. It was likely indicate that orchard location had significant effect on fruit quality, which was in accordance 246 with the study by Shiri et al. [24], who revealed the significant difference in 
247

biochemical compounds of 'Hayward' kiwifruit fruit sampled from two different commercial "Hayward" orchards in the north of Iran . Furthermore, a growing tonnage of evidences have illustrated the closely relationship between soil property and fruit quality in many fruit species, e.g., in citrus [25], blueberry [3], apple [5]. Also, our finding explicated correlated relationship between soil nutrient and fruit quality of kiwifruit, among which soil AN has significantly negative correlation with fruit TA $\left(R=-.955^{* *}\right)$ and AFe showed significant positive correlation with fruit TSS $\left(R=0.838^{*}\right)$. SS has significantly positive correlation with $\mathrm{FW}\left(R=0.813^{*}\right)$. The level of SS in fruit closely correlated with photosynthetic capacity of tree, and the higher the ability can be conducive to the accumulation of dry matter and therefore enhancement of fruit mass, which was in accordance with the evidence from Bertin et al [26], who illustrated that the total photosynthetically active radiation (PAR) received during the production stage from flowering to harvest has obvious correlation with the fresh mass of tomato fruit . However, according to the report published by El-Gizawy et al. [27], increasing shading levels from $35 \%$ to $63 \%$ increased the TA in tomato fruit, it declared that the photosynthetic capacity has negative correlation with TA, which was consistent with our results that SS was remarkably and negatively correlated with TA $(R=-0.821 *)$.

It is well known that the synergistic and antagonistic effects existing among soil nutrients, which will affect the availability of soil nutrient, and therefore has an great impact on its uptake by crops [28,29]. Based on the CCA and SMLR, our investigation indicated that soil AN content has positive correlation with $\mathrm{FW}$, which 
was in accordance with the evidence from Hipps et al [30], who explicated that the enhancement of nitrogen fertiliser application could enhance the FW of apple. Moreover, we found that soil AN and AFe content were positively related to the fruit SS and TSS concentration, respectively, which were in agreement with results of PCA. Lindsay [31] who previously reported that the activity of Fe in soil solution was highly PH-dependent. The significantly positive effect of soil AFe on fruit TA level was presented, in the current work, by a combination of CCA and SMLR. It is likely that soil AFe had an antagonistic effect against soil PH [32]. Soil PH, however, is one of the most important soil chemical properties in determining plant growth of nutrient uptake, and its effect on fruit quality was mainly achieved through the uptake of soil nutrients by plants [33,34].

\section{Conclusion}

Our study provided useful information on the status of soil property in Guangzhong plain of Northwest China, and its effect on the performance of fruit quality of 'Hayward' cultivar. The content of SOM was positively related to the measured soil nutrients except for the soil PH. It was indicated that the effects of soil properties somewhat varied among 'Hayward' fruit qualities. Among these fruit quality performance, FW and SS mainly affected by soil AN, and FI affected by soil AB and 
$\mathrm{AFe}$ and $\mathrm{PH}$. The effects of soil $\mathrm{PH}$ on fruit quality is probably achieved, however,

affecting the uptake of soil nutrients.

291

292

293

294

295

296

297

298

299

300

301

302

303

\section{Acknowledgments}

The project was supported by grants from the High-level Innovation Talent Program of Guizhou Province, P. R. China.

\section{Author Contributions}

Conceptualization: Kaibin Guo, Zhen Guo, Guang Qiao.

Data curation: Kaibin Guo, Zhen Guo.

Formal analysis: Yun Guo.

Funding acquisition: Yun Guo, Guang Qiao.

Investigation: Kaibin Guo, Zhen Guo, Guang Qiao.

Methodology: Guang Qiao.

Project administration: Yun Guo, Guang Qiao.

Resources: Guang Qiao.

Software: Kaibin Guo, Yun Guo.

Supervision: Guang Qiao. 
Writing - original draft: Kaibin Guo.

Writing - review \& editing: Kaibin Guo, Zhen Guo, Guang Qiao.

\section{References}

1. Collins A R. Kiwifruit as a modulator of DNA damage and DNA repair[J]. Advances in Food \& grown in Italy[J]. New Zealand Journal of Experimental Agriculture, 1991, 19(4):4.341-344. 

10(10):1647-1660. Properties and Their Relationships to Kiwifruit Quality[J]. Communications in Soil Science and Plant Analysis, 2011, 42(3): 332-357. nutritional plant status, fruit quality and yield[J]. Acta Horticulturae, 2015(1096):79-86. microbial parameters as influenced by catch crops and straw management[J]. Zemdirbyste-agriculture, 2013, 100(1):9-18. 
344 chronosequence in western Kenya[J]. Agriculture Ecosystems \& Environment, 2011, 141(1):86-99.

345 16. Gupta S, Gajbhiye VT. Simple methods for dithiopyr residue analysis in soil, water and plant 346 materials[J]. Annals of Plant Protection Sciences, 2000:79-83.

17. Olsen, S.R., Cole, C.V., Watanabe, F.S., Dean, L.A. 1954. Estimation of available phosphorus in

19. Feng J, Wen Z M, An S S, et al. Soil nutrient assessment based on attribute recognition model in the Loess Plateau of China[J]. Springerplus, 2013, 2(1):1-6. nutrients variability in Northeast China[J]. Nutrient cycling in agroecosystems, 2011, 89(3):427-438. 55(3):110-120. 
364

365

366

367

368

369

370

371

372

373
24. Shiri M A, Ghasemnezhad M, Fatahi Moghadam J, et al. Enhancing and Maintaining Nutritional Quality and Bioactive Compounds of "Hayward" Kiwifruit: Comparison of the Effectiveness of Different CaCl2 Spraying Times[J]. Journal of Food Processing \& Preservation, 2016, 40(5):850-862.

25. Singh S. Soil analysis based diagnostic norms for Indian citrus cultivar[J]. Communications in Soil Science \& Plant Analysis, 2002, 33(11-12):1689-1706.

26. Bertin N, Guichard S, Leonardi C, et al. Seasonal evolution of the quality of fresh glasshouse tomatoes under Mediterranean conditions, as affected by air vapour pressure deficit and plant fruit load.[J]. Annals of Botany, 2000, 85(6):741-750.

27. El Gizawy, A.M., Abdallah, M.M.F., Gomaa, H.M., Mohamed, S.S., 1992. Effect of different shading levels on tomato plants yield and fruit quality. Acta Hortic.323, 349-354.

28. Abbasi M K, Yousra M . Synergistic effects of biofertilizer with organic and chemical N sources in improving soil nutrient status and increasing growth and yield of wheat grown under greenhouse conditions[J]. Plant Biosystems-An International Journal Dealing with all Aspects of Plant Biology, 2012, 146(sup1):181-189.

29. Akinnifesi F K, Makumba W, Sileshi G, et al. Synergistic effect of inorganic N and P fertilizers and organic inputs fromGliricidia sepiumon productivity of intercropped maize in Southern Malawi[J].

Plant and Soil, 2007, 294(1-2):203-217.

30. Hipps N A, Perring M A . Effects of soil management systems and nitrogen fertiliser on the firmness and mean fruit weight of Cox's Orange Pippin apples at harvest[J]. Journal of the Science of Food \& Agriculture, 2010, 48(4):507-510. 

of Agricultural Science, 1983, 100(3):607-611. on Root Growth, Nutrient Uptake and Crop Growth of Potato[J]. European Journal of Plant Pathology, 1999, 105(1):61-76. 